University of South Carolina

Scholar Commons

3-2009

\title{
Physical and Social Contexts of Physical Activities Among Adolescent Girls
}

JoAnne Kuo

Kathryn H. Schmitz

Kelly R. Evenson

Thomas L. McKenzie

Jared B. Jobe

See next page for additional authors

Follow this and additional works at: https://scholarcommons.sc.edu/

sph_physical_activity_public_health_facpub

Part of the Public Health Commons

\section{Publication Info}

Published in Journal of Physical Activity and Health, Volume 6, Issue 2, 2009, pages 144-152.

Kuo, J., Schmitz, K. H., Evenson, K. R., McKenzie, T. L., Jobe, J. B., Rung, A. L., ... Pate, R. R. (2009).

Physical and social contexts of physical activities among adolescent girls. Journal of Physical Activity and Health, 6(2), 144-152.

(C) Journal of Physical Activity and Health, 2009, Human Kinetics

This Article is brought to you by the Physical Activity and Public Health at Scholar Commons. It has been accepted for inclusion in Faculty Publications by an authorized administrator of Scholar Commons. For more information, please contact digres@mailbox.sc.edu. 


\section{Author(s)}

JoAnne Kuo, Kathryn H. Schmitz, Kelly R. Evenson, Thomas L. McKenzie, Jared B. Jobe, Ariane L. Rung, Joel Gittelsohn, and Russell R. Pate 


\title{
Physical and Social Contexts of Physical Activities Among Adolescent Girls
}

\author{
JoAnn Kuo, Kathryn H. Schmitz, Kelly R. Evenson, Thomas L. McKenzie, Jared B. Jobe, \\ Ariane L. Rung, Joel Gittelsohn, and Russell R. Pate
}

\begin{abstract}
Background: With limited opportunities for physical activity during school hours, it is important to understand the contexts of physical activities done outside of school time. Given the importance of physical and social aspects of environments, the purpose of this study was to describe where and with whom girls participate in physical activities outside of school. Methods: Participants were 1925 sixth-grade girls in the Trial of Activity for Adolescent Girls (TAAG). At baseline, they completed a 3-day physical activity recall (3DPAR), reporting the main activity performed during 30-minute intervals and the physical and social contexts of physical activities. Results: The most frequently reported physical activities done outside of school time were house chores, walking (for transportation or exercise), dance, basketball, playing with younger children, and running or jogging. The most common location for these activities was at home or in the neighborhood. With the exception of household chores, these activities were typically done with at least one other person. Conclusions: Interventions that pro-
\end{abstract}

\footnotetext{
Kuo is with the Dept of Kinesiology, University of Maryland, College Park, MD 20742. Schmitz is with the Center for Clinical Epidemiology and Biostatistics, University of Pennsylvania, Philadelphia, PA 19104. Evenson is with the Dept of Epidemiology, University of North Carolina at Chapel Hill, NC 27514. McKenzie is with the School of Exercise and Nutritional Sciences, San Diego State University, San Diego, CA 92182. Jobe is with the Division of Prevention and Population Sciences, National Heart, Lung, and Blood Institute, Bethesda, MD 20892. Rung is with the Epidemiology Program, Louisiana State University School of Public Health, New Orleans, LA 70112. Gittelsohn is with the Dept of International Health, Johns Hopkins Bloomberg School of Public Health, Baltimore, MD 21205. Pate is with the Dept of Exercise Science, University of South Carolina, Columbia, SC 29208.
}

mote physical activities that can be done at or around home or developing supportive social networks for physical activity would be consistent with the current physical activity contexts of adolescent girls.

Keywords: environment, 3-day physical activity recall, out-of-school

Regular physical activity confers many health benefits. ${ }^{1}$ However, a national survey indicated that less than half of children age 9 to 13 years participate in organized physical activity during nonschool time, and nearly one-fourth do not engage in any free-time physical activity. ${ }^{2}$ Adolescence is a time during which lifelong behaviors, including physical activity, are established. However, physical activity levels decline considerably during this time period, particularly among girls. ${ }^{3-5}$ Other than physical education (PE) class, there are few opportunities for most adolescents to be physically active during school. Hence, it is particularly important to understand physical activities done outside of school time.

Ecological models focus on the physical (where) and social (with whom) environments in which behaviors, such as physical activity, take place. ${ }^{6,7}$ Physical environmental factors, such as access to equipment at home, school, or in the community, might interact with individual factors to influence physical activity. A study with sixth- and eighth-grade girls found that they were more likely to be more physically active if they had sports equipment at home. ${ }^{8}$ Girls were also more likely to report higher levels of physical activity if they had physical activity facilities near their home. Another study found that equipment accessibility, mediated by self-efficacy for overcoming barriers, was related to adolescent girls' physical activity. ${ }^{9}$ Supportive social environments might also prompt and reinforce physically active behaviors. For example, encouragement to be physically active by family and friends and participation in a physical activity with a friend were significantly associated with moderate-to-vigorous 
physical activity in adolescent girls. ${ }^{10}$ Hence, understanding the physical and social contexts of adolescent girls' physical activity might be helpful in developing effective interventions.

The purposes of the current study were to describe (a) where and with whom girls participate in the most frequently reported physical activities outside of school and (b) where and with whom girls of different racial/ ethnic backgrounds and weight-status groups participate in physical activity outside of school. Although recent studies have examined the types of physical activity that adolescent girls $\mathrm{do}^{11-14}$ and the physical and social contexts of physical activity, ${ }^{15}$ this is the first to examine the physical and social contexts in which different types of physical activity are done in a large, ethnically diverse sample of girls from different locations in the United States.

\section{Methods}

The Trial of Activity for Adolescent Girls (TAAG) was a group-randomized trial designed to develop and assess the efficacy of a school- and community-linked physical activity intervention for middle school girls. ${ }^{16}$ It used a social ecological model ${ }^{17}$ as its theoretical framework with 3 targets for change: the physical environment, the social environment, and the individual. TAAG involved 6 field centers (University of Maryland, University of South Carolina, University of Minnesota, Tulane University, University of Arizona, and San Diego State University), a data coordinating center (University of North Carolina at Chapel Hill), and the project office at the National Heart, Lung, and Blood Institute, National Institutes of Health. Six schools were recruited at each of the 6 field centers $(n=36$ schools $)$ and randomized within each center to either intervention or control conditions. This manuscript used baseline data only.

\section{Participants}

During the spring semester of the 2002-2003 school year, 60 sixth-grade girls were randomly selected from each of the 6 schools at the 6 TAAG field centers to undergo a series of baseline measurements, including body composition and self-report questionnaires. Of this random sample of 2160 girls, $80 \%$ provided parental consent and participant assent $(\mathrm{N}=1721)$. In addition, some field centers recruited all sixth-grade girls to participate in baseline questionnaires, resulting in a total sample size of 1925 girls for this study. The protocol was approved by the human subjects review board at each field center.

\section{Measurements}

Measurement coordinators from each field center were trained and certified at a centralized training. The measurement coordinators then trained and certified local measurement staff at each field center. The TAAG Mea- surement Committee provided oversight of all measurement. Data at each school were collected over at least 2 separate calendar weeks to minimize the school-level intraclass correlation between girls within a school. ${ }^{18}$

Participants completed the TAAG 3-Day Physical Activity Recall (3DPAR). They reported the types and contexts of the physical activities that they engaged in over the 3 days before administration. ${ }^{19}$ The 3DPAR has been validated in adolescent girls. ${ }^{20}$ To help girls recall activities, each day was divided into 30-minute blocks from $6 \mathrm{AM}$ to midnight. The 3DPAR provided a list of 70 sedentary and physical activities with code numbers, arranged in categories (eg, eating, sleeping, personal care, transportation, work, school, spare time, and physical activities). Participants recorded the code number of the predominant activity that they performed during each 30-minute block of time. In addition to activities occurring in sports, recreation, and fitness training, physical activities also included walking and biking for transportation and working, including house chores and yard work. Data on the physical and social contexts in which physical activity occurred (ie, where and with whom) were also collected. The physical context for transportation activities was the destination. The TAAG 3DPAR had 5 response options for physical location (ie, community facilities, outdoor public areas, other facilities, home or neighborhood, and school). Because community facilities could include outdoor public areas (eg, park, field), community facilities, outdoor public areas, and other facilities were collapsed into a single category labeled community facility so that 3 categories are reported herein-home or neighborhood, school, and community facility. The social context had 4 response options (ie, alone; with one other person; with several people [but not an organized program, class, or team]; and with an organized program, class, or team). One other person and several people were collapsed into a single category labeled with other person(s) so that 3 categories are reported herein-alone, with other person(s), and with an organized group.

Race/Ethnicity. Participants self-reported their race/ ethnicity on a checklist that included White, Black/African American, Hispanic, Asian, Native Hawaiian/Pacific Islander, American Indian/Alaska Native, and Other. They were asked to check as many categories as applied.

Weight Status. Participants' weight was measured twice to the nearest $0.1 \mathrm{~kg}$ on an electronic scale (Seca, Model 770, Hamburg, Germany). Their height was measured twice to the nearest $0.1 \mathrm{~cm}$ using a portable stadiometer (Shorr Height Measuring Board, Olney, MD). The average of each of the 2 measures was used to calculate body mass index (BMI, $\mathrm{kg} / \mathrm{m}^{2}$ ). BMI categories of underweight, normal weight, at risk for overweight, and overweight were derived from the 2000 Centers for Disease Control and Prevention (CDC) United States Growth Charts (http://www.cdc.gov/growthcharts/) using age-specific percentiles for females. Underweight 
was defined as below the 5th percentile. Normal weight was defined as at or above the 5 th percentile but below the 85th percentile. At risk for overweight was defined as at or above the 85 th percentile but below the 95 th percentile. Overweight was defined as at or above the 95th percentile.

\section{Statistical Analysis}

Only 30-minute blocks outside of school hours, when the participant was not sleeping, were examined. Blocks including the school start or end time (ie, school did not always start or end on the hour or half-hour) were considered outside of school hours if school time comprised less than 15 minutes of the 30-minute block.

The frequencies of physical activities reported in different contexts (ie, physical location and social context) were examined at both girl and block levels. A participant was classified as engaging in physical activity in a given context if she reported doing any physical activity in that context for at least one 30-minute block in the previous 3 days. Similarly, a participant was classified as engaging in a particular activity if she reported doing that activity for at least one 30-minute block in the previous 3 days. For each context and for physical activities reported by $10 \%$ or more of girls, the mean and standard deviation of the number of 30-minute blocks per day was determined among girls who were physically active in that context or did that physical activity. Differences in the distribution of 30-minute blocks across the different physical and social contexts for the most frequently reported physical activities and by race/ethnicity and weight status were tested for statistical significance using chi-square tests with alpha $=$ .0001 to control for multiple comparisons. If fewer than eight 30-minute blocks (ie, 4 hours) of nonsleeping activity outside of school time were reported for a given day, that day was excluded from the analyses $(n=32$ of 5694 days or $0.6 \%$ excluded). Data were analyzed using SAS version 9.1.

\section{Results}

Between 290 and 372 girls completed the 3DPAR at each of the 6 field centers. The sample was racially/ethnically diverse with nearly half reporting being White (45\%), followed by Hispanic (23\%), African American $(21 \%)$, multiple race (6\%), Asian (4\%), and American Indian $(0.7 \%)$. Based on measured height and weight, approximately two-thirds were classified as either underweight $(3 \%)$ or normal weight $(64 \%)$, and onethird were either at risk for overweight $(17 \%)$ or overweight $(16 \%)$.

Participants reported their activities for an average of 19.7 30-minute blocks/d outside of school time during the previous 3 days (Table 1). Nearly all girls (1785 or 93\%) reported doing a physical activity outside of school time for at least one 30-minute block. However, less than $20 \%$ of the blocks outside of school time (mean
$=3.8$ blocks $/ \mathrm{d}$ ) were spent doing physical activity. Most participants were physically active outside of school time in more than one context, 55\% were physically active in more than one physical location, and $59 \%$ were physically active in more than one social context (data not shown).

\section{General Physical Activity Context}

Table 1 lists the physical and social contexts for physical activities done outside of school time. Most girls $(80 \%)$ reported doing a physical activity outside of school time at home or in the neighborhood, and over half reported doing so at a community facility (52\%). Approximately one-fourth reported doing a physical activity at school outside of school time. Participants who reported doing a physical activity outside of school time at home/neighborhood or at a community facility did so for an average of 2.5 and 2.030 -minute blocks/d, respectively, compared with 1.030 -minute blocks/d at school.

Over three-fourths of participants reported doing a physical activity outside of school time with other person(s) (78\%), and over half reported doing so alone $(55 \%)$. Nearly $30 \%$ of participants reported doing a physical activity outside of school time with an organized group. Those reporting doing a physical activity outside of school time with other persons(s) did so for an average of 2.630 -minute blocks/d compared with 1.7 30-minute blocks/d if done alone and 1.4 30-minute blocks/d if done with an organized group.

\section{Context of Most Common Physical Activities}

Table 1 shows that the most common physical activities outside of school time were doing house chores (43\% of participants) and traveling by walking (36\% of participants). Other common physical activities included dancing $(25 \%)$, playing basketball (24\%), playing with younger children $(20 \%)$, walking for exercise (18\%), and running or jogging $(18 \%)$. Girls reporting these activities indicated they did them for an average of 0.8 to 1.3 30-minute blocks/d over the 3-day recall period. All other physical activities done outside of school time were reported by less than $10 \%$ of participants.

The physical context for each of the most frequently reported physical activities done outside of school time is shown in Table 2. Home/neighborhood was reported as the physical location for $45 \%$ or more of the blocks for which these physical activities were reported. Nearly all $(97 \%)$ of the blocks spent doing house chores were done at a home or in the neighborhood. Playing with younger children, walking for exercise, and running or jogging also tended to occur at a home or in the neighborhood $(83 \%, 62 \%$, and $67 \%$ of blocks, respectively). The percent of blocks spent doing the most frequently reported physical activities at home or in the neighborhood were all significantly different $(P<.0001)$, except 
Table 1 Physical Activity Context and Most Frequentlya Reported Physical Activities Outside of School Hours and Mean 30-Minute Blocks ${ }^{b}$

\begin{tabular}{|c|c|c|c|c|}
\hline Context or physical activity & $\mathbf{n}$ & $\%$ & $\begin{array}{l}\text { Average } \\
\text { blocks/d }\end{array}$ & SD \\
\hline Total $^{\mathrm{c}}$ & 1925 & 100.0 & 19.65 & 3.87 \\
\hline Any activity ${ }^{\mathrm{d}}$ & 1785 & 100.0 & 3.76 & 2.63 \\
\hline \multicolumn{5}{|l|}{ Physical context $\mathrm{e}^{\mathrm{e}}$} \\
\hline home or neighborhood & 1532 & 79.6 & 2.51 & 2.08 \\
\hline school & 534 & 27.7 & 1.03 & 0.92 \\
\hline community facility ${ }^{\mathrm{f}}$ & 943 & 51.6 & 2.04 & 1.92 \\
\hline \multicolumn{5}{|l|}{ Social context ${ }^{\mathrm{e}}$} \\
\hline alone & 1064 & 55.3 & 1.36 & 1.29 \\
\hline with other person $(\mathrm{s})^{\mathrm{g}}$ & 1510 & 78.4 & 2.62 & 2.15 \\
\hline with an organized group ${ }^{\mathrm{h}}$ & 576 & 29.9 & 1.74 & 1.56 \\
\hline \multicolumn{5}{|l|}{ Physical activity ${ }^{\mathrm{i}}$} \\
\hline doing house chores & 818 & 42.5 & 1.04 & 0.91 \\
\hline travel by walking & 700 & 36.4 & 0.96 & 0.82 \\
\hline dance & 476 & 24.7 & 1.27 & 1.31 \\
\hline basketball & 460 & 23.9 & 1.28 & 1.12 \\
\hline playing with younger children & 385 & 20.0 & 1.29 & 1.47 \\
\hline walking for exercise & 343 & 17.8 & 0.92 & 0.88 \\
\hline running or jogging & 341 & 17.7 & 0.76 & 0.67 \\
\hline
\end{tabular}

${ }^{a}$ Most frequently refers to physical activities that $10 \%$ or more of participants reported doing for most of at least 1 block over the previous 3 days.

${ }^{\mathrm{b}}$ Block is a 30-minute block of time for which participants reported what activity they were doing most of that time.

${ }^{c}$ Total $n(\%)$ refers to participants who completed the questionnaire. Total blocks refers to number of blocks per day outside of school hours during which participants were not sleeping.

${ }^{\mathrm{d}}$ Any activity $n(\%)$ refers to participants who reported physical activity for at least 1 block over the previous 3 days. Any activity blocks refers to blocks per day over the previous 3 days during which participants were physically active outside of school hours.

${ }^{\mathrm{e}}$ Context blocks refers to number of blocks per day over the previous 3 days during which physical activity was done in that context among participants who were active in that context.

${ }_{\mathrm{f}}^{\mathrm{f}}$ Community facility includes community facilities, outdoor public areas, and other facilities.

g Other person $(s)$ includes one other person and several other people but not an organized program, class, or team.

${ }^{\text {h }}$ Organized group includes organized programs, classes, or teams.

${ }^{\text {i }}$ Physical activity blocks refers to number of blocks per day over the previous 3 days for which that activity was done among participants who did it.

traveling by walking and dancing $(P=.45)$, dancing and walking for exercise $(P=.001)$, and walking for exercise and running or jogging $(P=.05)$. Community facility was reported as the physical location for approximately one-third of blocks for dancing (38\%), playing basketball (33\%), and walking for exercise (32\%). The percent of blocks spent doing the most frequently reported physical activities at a community facility were all significantly different $(P<.0001)$, except traveling by walking and running or jogging $(P=.12)$, dancing and playing basketball $(P=.001)$, dancing and walking for exercise $(P=.005)$, basketball and walking for exercise $(P=.89)$, basketball and running or jogging $(P=$ $.005)$, and walking for exercise and running or jogging $(P=.02)$. School was a common physical location for 2 physical activities done outside of school time- traveling by walking ( $22 \%$ of blocks) and playing basketball (22\% of blocks). The other most commonly reported physical activities outside of school time occurred at school for less than $7 \%$ of blocks. The percent of blocks spent doing the most frequently reported physical activ- ities at school were all significantly different $(P<.0001)$, except traveling by walking and playing basketball $(P=$ $.83)$, dancing and walking for exercise $(P=.24)$, dancing and running or jogging $(P=.77)$, and walking for exercise and running or jogging $(P=.47)$.

The social context for each of the most commonly reported physical activities done outside of school time by 30 -minute block is shown in Table 3 . Each of these physical activities was done with at least one other person for over $40 \%$ of blocks. The vast majority (93\%) of blocks that were spent playing with younger children were with someone else. Traveling by walking, walking for exercise, and running or jogging also frequently occurred with at least one other person $(72 \%, 62 \%$, and $63 \%$ of blocks, respectively). The percent of blocks spent doing the most frequently reported physical activities with at least one other person were all significantly different $(P<.0001)$, except basketball and walking for exercise $(P=.04)$, basketball and running or jogging $(P$ $=.007)$, and walking for exercise and running or jogging $(P=.47)$. House chores tended to be done alone 
Table 2 Physical Context of Most Frequentlya Reported Physical Activities Outside of School Hours

\begin{tabular}{|c|c|c|c|c|c|c|c|}
\hline \multirow[b]{2}{*}{ Physical activity } & \multirow[b]{2}{*}{$\begin{array}{c}\text { Total } \\
\text { blocks }^{\mathrm{b}}\end{array}$} & \multicolumn{2}{|c|}{$\begin{array}{c}\text { Home or } \\
\text { neighborhoodc }\end{array}$} & \multicolumn{2}{|c|}{ Schoold } & \multicolumn{2}{|c|}{$\begin{array}{c}\text { Community } \\
\text { facility }^{\mathrm{e}}\end{array}$} \\
\hline & & $\mathbf{n}$ & $\%$ & $\mathbf{n}$ & $\%$ & $\mathbf{n}$ & $\%$ \\
\hline Total & 20,062 & 11,480 & 59.9 & 1650 & 8.6 & 6046 & 31.5 \\
\hline Doing house chores & 2526 & 2318 & 96.5 & 14 & 0.6 & 71 & 3.0 \\
\hline Travel by walking & 2017 & 1039 & 54.1 & 421 & 21.9 & 459 & 23.9 \\
\hline Dance & 1800 & 954 & 55.4 & 117 & 6.8 & 651 & 37.8 \\
\hline Basketball & 1760 & 771 & 45.2 & 379 & 22.2 & 555 & 32.6 \\
\hline Playing with younger children & 1484 & 1167 & 83.2 & 27 & 1.9 & 209 & 14.9 \\
\hline Walking for exercise & 934 & 554 & 62.1 & 50 & 5.6 & 288 & 32.3 \\
\hline Running or jogging & 775 & 485 & 66.7 & 47 & 6.5 & 195 & 26.8 \\
\hline
\end{tabular}

${ }^{a}$ Most frequently refers to physical activities that $10 \%$ or more of participants reported doing for most of at least 1 block over the previous 3 days.

${ }^{\mathrm{b}}$ Block is a 30-minute block of time for which participants reported what activity they were doing most of that time.

${ }^{\mathrm{c}}$ Proportions of blocks spent at home or in the neighborhood were all different $(P<.0001)$, except between traveling by walking and dancing $(P=$ $.45)$, dancing and walking for exercise $(P=.001)$, and walking for exercise and running or jogging $(P=.05)$.

${ }^{\mathrm{d}}$ Proportions of blocks spent at school were all different $(P<.0001)$, except between traveling by walking and basketball $(P=.83)$, dancing and walking for exercise $(P=.24)$, dancing and running or jogging $(P=.77)$, and walking for exercise and running or jogging $(P=.47)$.

${ }^{\mathrm{e}}$ Community facility includes community facilities, outdoor public areas, and other facilities. Proportions of blocks spent at a community facility were all different $(P<.0001)$, except between traveling by walking and running or jogging $(P=.12)$, dancing and basketball $(P=.001)$, dancing and walking for exercise $(P=.005)$, basketball and walking for exercise $(P=.89)$, basketball and running or jogging $(P=.005)$, and walking for exercise and running or jogging $(P=.02)$.

Table 3 Social Context of Most Frequentlya Reported Physical Activities Outside of School Hours

\begin{tabular}{|c|c|c|c|c|c|c|c|}
\hline \multirow[b]{2}{*}{ Physical activity } & \multirow[b]{2}{*}{$\begin{array}{c}\text { Total } \\
\text { blocks }^{b}\end{array}$} & \multicolumn{2}{|c|}{ Alone $^{c}$} & \multicolumn{2}{|c|}{$\begin{array}{l}\text { With other } \\
\text { person(s) }\end{array}$} & \multicolumn{2}{|c|}{$\begin{array}{c}\text { With an organized } \\
\text { group }^{\mathrm{e}}\end{array}$} \\
\hline & & $\mathbf{n}$ & $\%$ & $\mathbf{n}$ & $\%$ & $\mathbf{n}$ & $\%$ \\
\hline Total & 20,062 & 4305 & 22.5 & 11,798 & 61.8 & 2995 & 15.7 \\
\hline Doing house chores & 2526 & 1372 & 57.3 & 996 & 41.6 & 26 & 1.1 \\
\hline Travel by walking & 2017 & 484 & 25.5 & 1366 & 71.9 & 51 & 2.7 \\
\hline Dance & 1800 & 444 & 25.5 & 858 & 49.3 & 437 & 25.1 \\
\hline Basketball & 1760 & 160 & 9.4 & 978 & 57.5 & 562 & 33.1 \\
\hline Playing with younger children & 1484 & 66 & 4.7 & 1298 & 92.5 & 39 & 2.8 \\
\hline Walking for exercise & 934 & 306 & 34.9 & 541 & 61.7 & 30 & 3.4 \\
\hline Running or jogging & 775 & 229 & 31.4 & 463 & 63.4 & 38 & 5.2 \\
\hline
\end{tabular}

${ }^{a}$ Most frequently refers to physical activities that $10 \%$ or more of participants reported doing for most of at least 1 block over the previous 3 days.

${ }^{\mathrm{b}}$ Block is a 30-minute block of time for which participants reported what activity they were doing most of that time.

${ }^{\mathrm{c}}$ Proportions of blocks spent alone were all different $(P<.0001)$, except between traveling by walking and dancing $(P=.96)$, traveling by walking and running or jogging $(P=.002)$, dancing and running or jogging $(P=.003)$, and walking for exercise and running or jogging $(P=.14)$.

${ }^{\mathrm{d}}$ Other person $(s)$ includes one other person and several other people but not in an organized program, class, or team. Proportions of blocks spent with at least one other person were all different $(P<.0001)$, except between basketball and walking for exercise $(P=.04)$, basketball and running or jogging $(P=.007)$, and walking for exercise and running or jogging $(P=.47)$.

e Organized group includes organized programs, classes, or teams. Proportions of blocks spent with an organized group were all different $(P<$ $.0001)$, except between traveling by walking and playing with younger children $(P=.87)$, traveling by walking and walking for exercise $(P=.28)$, and traveling by walking and running or jogging $(P=.001)$, playing with younger children and walking for exercise $(P=.38)$, playing with younger children and running or jogging $(P=.004)$, and walking for exercise and running or jogging $(P=.08)$.

(57\% of blocks). Other physical activities done outside of school time that were often done alone included traveling by walking, dancing, walking for exercise, and running or jogging $(26 \%, 26 \%, 35 \%$, and $31 \%$ of blocks, respectively). The percent of blocks spent doing the most frequently reported physical activities alone were all significantly different $(P<.0001)$, except traveling by walking and dancing $(P=.96)$, traveling by walking and running or jogging $(P=.002)$, dancing and running or jogging $(P=.003)$, and walking for exercise and running or jogging $(P=.14)$. Dance and basketball were frequently done with an organized group (25\% and 33\% of blocks, respectively), whereas the other most common physical activities were done with an organized group 
for less than $6 \%$ of blocks. The percent of blocks spent doing the most frequently reported physical activities with an organized group were all significantly different $(P<.0001)$, except traveling by walking and playing with younger children $(P=.87)$, traveling by walking and walking for exercise $(P=.28)$, traveling by walking and running or jogging $(P=.001)$, playing with younger children and walking for exercise $(P=.38)$, playing with younger children and running or jogging $(P=$ $.004)$, and walking for exercise and running or jogging $(P=.08)$.

\section{General Physical Activity Context by Race/Ethnicity and Weight Status}

The physical context of physical activity outside of school time by 30 -minute block by race/ethnicity and weight status is shown in Table 4 . White girls $(55 \%)$ spent relatively fewer physically active blocks at home or in the neighborhood than did Hispanic (63\%) or African American $(65 \%)$ girls $(P<.0001)$. Under- or normal-weight girls $(57 \%)$ spent relatively fewer physically active blocks at home or in the neighborhood than did at risk for overweight (65\%) or overweight (64\%) girls $(P<.0001)$. Other racial/ethnic and weight-status differences in the percent of physically active blocks outside of school time spent at home or in the neighborhood were not significant $(P>.004)$. White girls $(36 \%)$ spent relatively more physically active blocks at a community facility than did other racial/ethnic groups $(25 \%$ to $30 \% ; P<.0001)$. Under- or normal-weight girls (34\%) spent relatively more physically active blocks at a community facility than did at risk for overweight $(26 \%)$ or overweight $(29 \%)$ girls $(P<.0001)$. Other racial/ethnic and weight-status differences in the percent of physically active blocks outside of school time spent at a community facility were not significant $(P>$ $.001)$. Asian girls (14\%) spent relatively more physically active blocks outside of school time at school than did White (9\%), African American (9\%), or Hispanic $(7 \%)$ girls $(P<.0001)$. The difference between White and Hispanic girls approached statistical significance $(P$ $=.0005)$. Overweight girls (7\%) spent relatively fewer physically active blocks outside of school time at school than did at risk for overweight girls $(9 \% ; P<.0001)$. The difference between overweight and under- or normal-weight (9\%) girls approached statistical significance $(P=.0002)$. Other racial/ethnic and weight-status differences in the percent of physically active blocks outside of school time spent at school were not significant $(P>.004)$.

The social context of physical activity outside of school time by 30 -minute block by race/ethnicity and weight status is shown in Table 5. White (56\%) and Asian (54\%) girls spent relatively fewer physically active blocks with at least one other person than did Hispanic $(63 \%)$ or African American $(70 \%)$ girls $(P<$ $.0001)$. Other racial/ethnic and all the weight-status differences in the percent of physically active blocks outside of school time spent with at least one other person

Table 4 Physical Context of Physical Activity Outside of School Hours by Race/Ethnicity and Weight Status

\begin{tabular}{|c|c|c|c|c|c|c|c|}
\hline \multirow[b]{2}{*}{ Physical activity } & \multirow[b]{2}{*}{ Total blocks ${ }^{a}$} & \multicolumn{2}{|c|}{$\begin{array}{c}\text { Home or } \\
\text { neighborhood }^{b}\end{array}$} & \multicolumn{2}{|c|}{ Schoolc } & \multicolumn{2}{|c|}{$\begin{array}{c}\text { Community } \\
\text { facility }^{d}\end{array}$} \\
\hline & & $\mathbf{n}$ & $\%$ & $\mathbf{n}$ & $\%$ & $\mathbf{n}$ & $\%$ \\
\hline Total & 20,062 & 11,480 & 59.9 & 1650 & 8.6 & 6046 & 31.5 \\
\hline \multicolumn{8}{|l|}{ Race/Ethnicity } \\
\hline White & 9119 & 5016 & 55.0 & 816 & 8.9 & 3287 & 36.0 \\
\hline Hispanic & 4350 & 2751 & 63.2 & 312 & 7.2 & 1287 & 29.6 \\
\hline African American & 3457 & 2241 & 64.8 & 308 & 8.9 & 908 & 26.3 \\
\hline Asian & 678 & 411 & 60.6 & 95 & 14.0 & 172 & 25.4 \\
\hline \multicolumn{8}{|l|}{ Weight status ${ }^{\mathrm{e}}$} \\
\hline under or normal weight & 12,695 & 7296 & 57.5 & 1106 & 8.7 & 4293 & 33.8 \\
\hline at risk for overweight & 3195 & 2074 & 64.9 & 303 & 9.5 & 818 & 25.6 \\
\hline overweight & 2957 & 1900 & 64.3 & 195 & 6.6 & 862 & 29.2 \\
\hline
\end{tabular}

${ }^{a}$ Block is a 30-minute block of time for which participants reported what activity they were doing most of that time.

${ }^{\mathrm{b}}$ Proportions of blocks spent at home or in the neighborhood were different $(P<.0001)$ between White girls and Hispanic and African American girls and between under- or normal-weight girls and at risk for overweight and overweight girls. Other group differences were not significant $(P>$ $.004)$.

${ }^{\mathrm{c}}$ Proportions of blocks spent at school were different $(P<.0001)$ between Asian girls and White, Hispanic, and African American girls and between at risk for overweight and overweight girls. Difference between White and Hispanic girls $(P=.0005)$ and between under- or normal-weight and overweight girls approached statistical significance $(P=.0002)$. Other group differences were not significant $(P>.004)$.

${ }^{d}$ Community facility includes community facilities, outdoor public areas, and other facilities. Proportions of block spent at a community facility were different $(P<.0001)$ between White girls and Hispanic, African American, and Asian girls and between under- or normal-weight girls and at risk for overweight and overweight girls. Other group differences were not significant $(P>.001)$.

${ }^{\mathrm{e}}$ Under or normal weight is defined as $<85$ th age-specific BMI percentile for girls, at risk for overweight as 85 th to $<95$ th percentile, and overweight as $\geq 95$ th percentile. 
Table 5 Social Context of Physical Activity Outside of School Hours by Race/Ethnicity and Weight Status

\begin{tabular}{|c|c|c|c|c|c|c|c|}
\hline \multirow[b]{2}{*}{ Physical activity } & \multirow{2}{*}{$\begin{array}{c}\text { Total } \\
\text { blocks }^{a}\end{array}$} & \multicolumn{2}{|c|}{ Alone $^{b}$} & \multicolumn{2}{|c|}{$\begin{array}{l}\text { With other } \\
\text { person(s) }\end{array}$} & \multicolumn{2}{|c|}{$\begin{array}{c}\text { With an organized } \\
\text { group }^{d}\end{array}$} \\
\hline & & $\mathbf{n}$ & $\%$ & $\mathbf{n}$ & $\%$ & $\mathbf{n}$ & $\%$ \\
\hline Total & 20,062 & 4305 & 22.5 & 11,798 & 61.8 & 2995 & 15.7 \\
\hline \multicolumn{8}{|l|}{ Race/Ethnicity } \\
\hline White & 9067 & 2031 & 22.4 & 5091 & 56.1 & 1945 & 21.5 \\
\hline Hispanic & 3814 & 956 & 25.1 & 2396 & 62.8 & 462 & 12.1 \\
\hline African American & 3430 & 736 & 21.5 & 2388 & 69.6 & 306 & 8.9 \\
\hline Asian & 681 & 178 & 26.1 & 371 & 54.5 & 132 & 19.4 \\
\hline \multicolumn{8}{|l|}{ Weight status ${ }^{\mathrm{e}}$} \\
\hline under or normal weight & 12,613 & 2722 & 21.6 & 7692 & 61.0 & 2199 & 17.4 \\
\hline at risk for overweight & 3192 & 735 & 23.0 & 2026 & 63.5 & 431 & 13.5 \\
\hline overweight & 2961 & 776 & 26.2 & 1896 & 64.0 & 289 & 9.8 \\
\hline
\end{tabular}

a Block is a 30-minute block of time for which participants reported what activity they were doing most of that time.

${ }^{\mathrm{b}}$ Proportions of blocks spent alone were different $(P<.0001)$ between under- or normal-weight girls and overweight girls. Other group differences were not significant $(P>.003)$.

${ }^{c}$ Other person $(s)$ includes one other person and several other people but not an organized program, class, or team. Proportions of blocks spent with at least one other person were different $(P<.0001)$ between White and Asian girls compared with Hispanic and African American girls. Other group differences were not significant $(P>.002)$.

${ }^{\mathrm{d}}$ Organized group includes organized programs, classes, or teams. Proportions of blocks spent with an organized group were different $(P<.0001)$ between White and Asian girls compared with Hispanic and African American girls and all weight-status groups. Other group differences were not significant $(P \geq .01)$.

${ }^{\mathrm{e}}$ Under or normal weight is defined as $<85$ th age-specific BMI percentile for girls, at risk for overweight as 85 th to $<95$ th percentile, and overweight as $\geq 95$ th percentile.

were not significant $(P>.002)$. Overweight girls $(26 \%)$ spent relatively more physically active blocks alone than did under- or normal-weight girls $(22 \% ; P<.0001)$. All the racial/ethnic and the other weight-status differences in the percent of physically active blocks outside of school time spent alone were not significant $(P>$ $.003)$. White (21\%) and Asian (19\%) girls spent relatively more physically active blocks with an organized group than did Hispanic (12\%) or African American $(9 \%)$ girls $(P<.0001)$. Under- or normal-weight girls (17\%) spent relatively more physically active blocks with an organized group than did at risk for overweight girls $(14 \% ; P<.0001)$, which was greater than among overweight girls $(10 \% ; P<.0001)$. The differences in the percentages of physically active blocks outside of school time spent with an organized group between White and Asian girls $(P=.20)$ and Hispanic and African American girls $(P=.01)$ were not significant.

\section{Discussion}

Increased attention is being paid to the role of aspects of the physical (where) and social (with whom) environments in physical activity participation. The current study examined the physical and social contexts of the physical activities done outside of school time among a large, diverse sample of adolescent girls from different locations across the United States. The most common location for the most frequently reported physical activities outside of school time was at home or in the neighborhood. With the exception of household chores, these activities were usually done with at least one other person. The proportions of blocks spent in the different physical and social contexts were similar for walking for exercise and running or jogging. In addition, the proportions spent in the different locations were similar for walking for exercise and dancing. Hispanic and African American girls had similar proportions of blocks spent in the different physical and social contexts, and White and Asian girls had similar proportions spent in the different social contexts.

Adolescent girls' physical activity outside of school time might tend to occur at home or in the neighborhood because they might be more convenient than other locations, particularly for girls who have limited mobility outside of the home or school environments. A previous study showed that parent transportation to physical activity locations was particularly important for middle school girls. ${ }^{21}$ The availability of equipment at home, neighborhood features, and school environment were each associated with physical activity among high school students, but convenient community facilities was not. ${ }^{22}$ Community facilities might be difficult to get to or too costly to join. ${ }^{23}$ Opportunities for being active at school might be scheduled at inconvenient times, ${ }^{23}$ 
and access to school facilities, particularly indoor facilities, might be limited. ${ }^{24}$

Several interventions that promoted developing social networks to support being physically active, such as setting up a buddy system, have been found to increase physical activity levels. ${ }^{25}$ In our study, most physical activities were done with at least one other person, but it is unclear whether the girls were being active with friends or family members because the 3DPAR did not make this distinction. Although parents and family are still important influences on adolescents, they are increasingly influenced by their peers. In one study, support from friends, but not parents or siblings, was associated with more physical activity among youth. ${ }^{26}$ Nonetheless, an adolescent's decision to be physically active or not can also be influenced by parents' expectations. ${ }^{23}$ Future research should examine the specific sources of companionship in adolescent physical activities.

The most commonly reported physical activities done outside of school time were doing house chores, walking (for transportation or exercise), dance, basketball, playing with younger children, and running or jogging. These findings are similar to other research with adolescent girls. In a study with 6th- to 8th-grade North Carolina students, the most frequently reported top-3 physical activities of girls included running, walking, bicycling, dancing, basketball, and housework. ${ }^{13}$ A study with 8th-grade girls living in South Carolina found that house chores, walking (for transportation or exercise), basketball, jogging or running, bicycling, working, and dancing were the most commonly reported physical activities. ${ }^{11}$ Results from the TAAG formative evaluation with another group of 6th- and 8th-grade girls indicated that the most common physical activities included indoor chores, running or jogging, dance, calisthenics, child care, and walking for exercise. ${ }^{12} \mathrm{~A}$ study with 7th- to 9th-grade Pittsburgh-area students found similar physical activities were common among girls, including basketball and running, but also found some different common physical activities, including softball, aerobics, bowling, and tennis. ${ }^{14}$ However, as noted earlier, none of these studies examined the physical or social contexts of physical activity. At least one study ${ }^{15}$ has examined the physical and social contexts of adolescent physical activity, but walking and exercise were the only physical activities examined. Similar to our study, Dunton and colleagues ${ }^{15}$ found that physical activity occurred most often with at least one other person (eg, friends, family members, classmates). It is unclear whether they were done with an organized group, unless participants were with classmates. In contrast with our study, Dunton et $\mathrm{al}^{15}$ found that physical activity occurred most often at school or outdoors followed by at home. Their study included school time, which might explain why they observed more activity at school than we did. Furthermore, activities done outdoors might have been done in the neighborhood.
Compared with previous studies of adolescent girls' physical activities, ${ }^{11-15}$ the current investigation used a larger, more diverse sample of girls from 6 different locations across the United States. Future studies should examine how individual factors, such as race/ethnicity and weight status, as well as socioeconomic status, might affect the contexts of specific types of physical activity. The 3DPAR allowed girls to report where and with whom they were physically active, allowing the examination of aspects of the physical and social environment. Furthermore, the 3DPAR can be used to identify the types of activities that girls do, which cannot be measured by accelerometers. The 3DPAR is, however, a self-report instrument and, thus, might be subject to poor recall and social-desirability bias. That is, the girls might have reported physical activities over sedentary activities to appear more physically active. Although the previous 3 days is a time frame that adolescent girls are likely to recall accurately, this time frame might not be representative of regular physical activity.

\section{Conclusions}

Outside of school time, adolescent girls in this study tended to be physically active at home or in the neighborhood. This suggests that availability and convenience are important and that physical activity interventions should consider promoting activities that could be done at or near home to help maintain physical activities of adolescent girls. Moreover, more physical activity opportunities at schools or community facilities could be made available or existing activities could be made more accessible to increase their use. The girls also tend to be physically active outside of school time with at least one other person. Interventions should teach adolescents the skills necessary to maintain and develop supportive social networks for physical activity. They should also help adolescents start building social support as part of the physical activity program, such as offering bring-a-friend or parent-child activities. In addition, interventions could teach adolescents skills to perform physical activities that could be done alone and familiarize them with organized physical activity programs. Hence, promoting contexts that are already being used might help maintain current levels of physical activity, while promoting less used contexts might help increase physical activity by supporting use of alternative contexts. This study contributes to the essential preceding step: understanding how the physical and social contexts vary for different activity types and different groups of girls.

\section{Acknowledgments}

This study was supported by grants from NIH/NHLBI (\#U01HL-66845, HL-66852, HL-66853, HL-66855, HL66856, HL-66857, and HL-66858). 


\section{References}

1. US Department of Health and Human Services. Physical Activity and Health: A Report of the Surgeon General. Atlanta, GA: US Dept of Health and Human Services, Centers for Disease Control and Prevention, National Center for Chronic Disease Prevention and Health Promotion; 1996.

2. Centers for Disease Control and Prevention (CDC). Physical activity levels among children aged 9-13 years-United States, 2002. MMWR Morb Mortal Wkly Rep. 2003;52(33):785-788.

3. Caspersen CJ, Pereira MA, Curran KM. Changes in physical activity patterns in the United States, by sex and cross-sectional age. Med Sci Sports Exerc. 2000;32:16011609.

4. Kimm SY, Glynn NW, Kriska AM, et al. Longitudinal changes in physical activity in a biracial cohort during adolescence. Med Sci Sports Exerc. 2000;32:14451454.

5. Trost SG, Pate RR, Sallis JF, et al. Age and gender differences in objectively measured physical activity in youth. Med Sci Sports Exerc. 2002;34:350-355.

6. McLeroy KR, Bibeau D, Steckler A, Glanz K. An ecological perspective on health promotion programs. Health Educ Q. 1988;15:351-377.

7. Sallis JF, Owen N. Ecological models. In: Glanz K, Lewis FM, Rimer BK, eds. Health Behavior and Health Education: Theory, Research, and Practice. San Francisco, CA: Jossey-Bass; 1997:403-424.

8. Evenson K, Birnbaum A, Bedimo-Rung A, et al. Girls' perception of physical environmental factors and transportation: reliability and association with physical activity and active transport to school. Int J Behav Nutr Phys Act. 2006;3:28.

9. Motl RW, Dishman RK, Ward DS, et al. Perceived physical environment and physical activity across one year among adolescent girls: self-efficacy as a possible mediator? J Adolesc Health. 2005;37:403-408.

10. Springer AE, Kelder SH, Hoelscher DM. Social support, physical activity and sedentary behavior among 6th-grade girls: a cross-sectional study. Int J Behav Nutr Phys Act. 2006;3:8.

11. Dowda M, Pate RR, Felton GM, et al. Physical activities and sedentary pursuits in African American and Caucasian girls. Res Q Exerc Sport. 2004;75:352-360.

12. Grieser M, Vu MB, Bedimo-Rung AL, et al. Physical activity attitudes, preferences, and practices in African American, Hispanic, and Caucasian girls. Health Educ Behav. 2006;33:40-51.
13. Harrell JS, Pearce PF, Markland ET, Wilson K, Bradley CB, McMurray RG. Assessing physical activity in adolescents: common activities of children in 6th-8th grades. J Am Acad Nurse Pract. 2003;15:170-178.

14. Aaron DJ, Storti KL, Robertson RJ, Kriska AM, LaPorte RE. Longitudinal study of the number and choice of leisure time physical activities from mid to late adolescence. Arch Pediatr Adolesc Med. 2002;156:1075-1080.

15. Dunton GF, Whalen CK, Jamner LD, Floro JN. Mapping the social and physical contexts of physical activity across adolescence using ecological momentary assessment. Ann Behav Med. 2007;34:144-153.

16. Stevens J, Murray DM, Catellier DJ, et al. Design of the Trial of Activity in Adolescent Girls (TAAG). Contemp Clin Trials. 2005;26:223-233.

17. Stokols D. Establishing and maintaining healthy environments: toward a social ecology of health promotion. Am Psychol. 1992;47:6-22.

18. Murray DM, Catellier DJ, Hannan PJ, et al. School-level intraclass correlation for physical activity in adolescent girls. Med Sci Sports Exerc. 2004;36:876-882.

19. McMurray RG, Ring KB, Treuth MS, et al. Comparison of two approaches to structured physical activity surveys for adolescents. Med Sci Sports Exerc. 2004;36:21352143.

20. Pate RR, Ross R, Dowda M, Trost SG, Sirard JR. Validation of a three-day physical activity recall instrument in female youth. Pediatr Exerc Sci. 2003;15:257-265.

21. Hoefer WR, McKenzie TL, Sallis JF, Marshall SJ, Conway TL. Parental provision of transportation for adolescent physical activity. Am J Prev Med. 2001;21:4851.

22. Fein AJ, Plotnikoff RC, Wild TC, Spence JC. Perceived environment and physical activity in youth. Int J Behav Med. 2004;11:135-142.

23. Dwyer JJM, Allison KR, Goldenberg ER, Fein AJ, Yoshida KK, Boutilier MA. Adolescent girls' perceived barriers to participation in physical activity. Adolescence. 2006;41:75-89.

24. O'Hara Tompkins N, Zizzi S, Zedosky L, Wright J, Vitullo E. School-based opportunities for physical activity in West Virginia public schools. Prev Med. 2004;39:834840.

25. Kahn EB, Ramsey LT, Brownson RC, et al. The effectiveness of interventions to increase physical activity: a systematic review. Am J Prev Med. 2002;22:73-107.

26. Duncan SC, Duncan TE, Strycker LA. Sources and types of social support in youth physical activity. Health Psychol. 2005;24:3-10. 